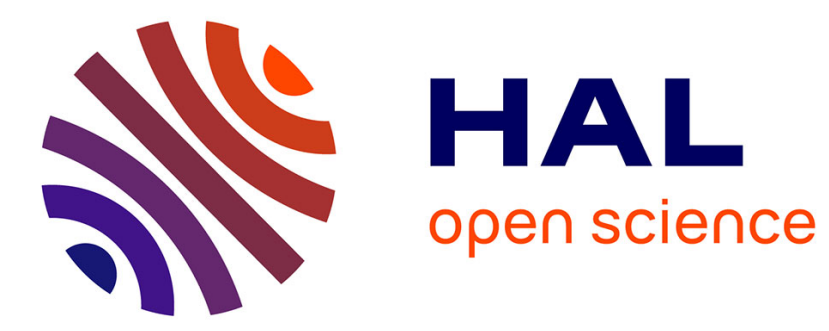

\title{
Four-wave mixing process induced by a self-phase modulated pulse in a hollow core capillary
}

Olivia Zurita-Miranda, Coralie Fourcade-Dutin, Pierre Béjot, Frederic Fauquet, Hervé Maillotte, Patrick Mounaix, Damien Bigourd

\section{- To cite this version:}

Olivia Zurita-Miranda, Coralie Fourcade-Dutin, Pierre Béjot, Frederic Fauquet, Hervé Maillotte, et al. Four-wave mixing process induced by a self-phase modulated pulse in a hollow core capillary. OSA Advanced Photonics Congress, Jul 2021, Washington DC, United States. hal-03425631v2

\section{HAL Id: hal-03425631 \\ https://hal.science/hal-03425631v2}

Submitted on 29 Nov 2021

HAL is a multi-disciplinary open access archive for the deposit and dissemination of scientific research documents, whether they are published or not. The documents may come from teaching and research institutions in France or abroad, or from public or private research centers.
L'archive ouverte pluridisciplinaire HAL, est destinée au dépôt et à la diffusion de documents scientifiques de niveau recherche, publiés ou non, émanant des établissements d'enseignement et de recherche français ou étrangers, des laboratoires publics ou privés. 


\title{
Four-wave mixing process induced by a self-phase modulated pulse in a hollow core capillary
}

\author{
Olivia Zurita-Miranda ${ }^{1,2^{*}}$, Coralie Fourcade-Dutin ${ }^{1}$, Pierre Béjot ${ }^{3}$, Frederic Fauquet ${ }^{1}$, Hervé Maillotte ${ }^{2}$, \\ Patrick Mounaix ${ }^{1}$ and Damien Bigourd ${ }^{1}$
}

\author{
${ }^{1}$ Laboratoire IMS, UMR CNRS 5218, University of Bordeaux, 33400 Talence, France \\ ${ }^{2}$ Institut FEMTO-ST, Département d'Optique, UMR CNRS 6174 -Université Bourgogne Franche-Comté, 25030 Besançon, France \\ ${ }^{3}$ Laboratoire Interdisciplinaire Carnot de Bourgogne UMR CNRS 6303, Université Franche-Comté, 2178 Dijon, France \\ *Correspondence: olivia.zuriat-miranda@u-bordeaux.fr
}

\begin{abstract}
In this work, we investigate the modal four waves mixing (FWM) process in an argon filled capillary appearing from the spectral broadening of a pump pulse injected in the fundamental mode. The edge of the spectrum at the low wavelength part seeds the FWM process to generate an high order mode in the near infrared.
\end{abstract}

\section{Introduction}

Nonlinear pulse propagation in multimode optical fibers have recently regained interest this last years for their additional degree of freedom enabling the manipulation of the temporal and spatial features [1,2]. Particularly, multimode properties of fibers allow the enhancement of nonlinear converter spectral band by using for example a Four Wave-Mixing (FWM) with modal phase matching [3]. In the case of a gas filled Hollow-Core Capillary (HCC) pumped by an ultra-short pulse, several investigations focus their attention on the nonlinear interaction of the modes through the self-focusing [4] or ionization processes [5]. In this work, we investigate the phase-matched modal FWM processes self-seeded by the spectral broadening of a pump pulse injected in the fundamental mode.

\section{Experiment}

In the experimental set-up, we used a $30 \mathrm{~cm}$ long $\mathrm{HCC}$ with a $150 \mu \mathrm{m}$ core diameter pumped by an ultra-short pulse delivered by a $1 \mathrm{kHz}$ Ti:Sa laser source ( $800 \mathrm{~nm}, 120 \mathrm{fs})$. The output energy is $170 \mu \mathrm{J}$. The HCC is placed inside a chamber with two 5-mm-thick windows and filled it with Argon at a pressure of $\sim 2$ bar. At the output chamber, the pulse is split by a dichroic mirror to separate the visible and infrared parts. The filtered beams are detected by specific spectrometers simultaneously and the beam profiles are recorded by a camera. From the pump beam profile (Fig. 2.a), we consider that only the fundamental mode is injected in the capillary. Fig. 2.a also shows the spectrum at the HCC output. The pulse propagates in the normal dispersion regime and the spectrum broadens mostly due to selfphase modulation (SPM) up to 700 and $900 \mathrm{~nm}$.

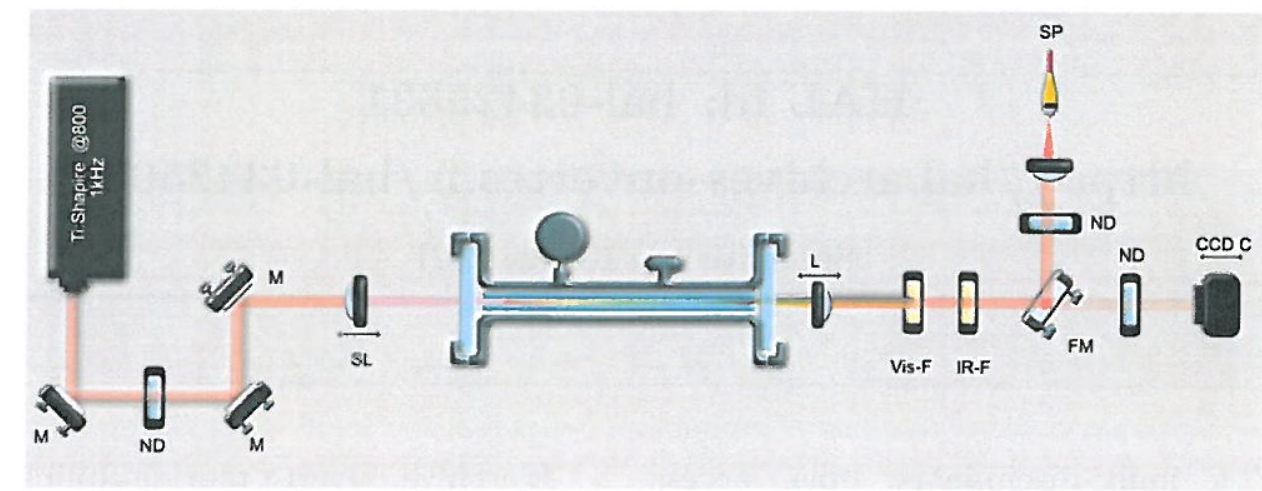

Figure 1. Experimental set up. SL Plano Convex lens; BS, beam splitter; ND absorptive neutral density filter; Vis-F, long-pass filter in visible region; IR-F, long-pass filter in infrared region; SP, Spectrometer; FM, Flip Mirror; M, Mirror. CCD C, Camera, L positive lens. 


\section{Results and discussion}

During the propagation, the pump pulse undergoes a symmetrical spectral broadening. At the HCC output, the high wavelength part $(>1000 \mathrm{~nm})$ of the spectrum is selected with a long-pass filter. By removing the central part of the pump, the edge of the spectrum is detected up to $1150 \mathrm{~nm}$ (Figure 2.b). According to the beam profile, this part actually propagates on a high order mode $\left(\mathrm{HE}_{21}\right)$ and appears from a FWM process seeded by a signal lying in the low wavelength side of the spectrum. Indeed, Figure 2.c shows the coherence length as the function of the wavelength and the pressure when the generated infrared profile can be the $\mathrm{HE}_{11}, \mathrm{HE}_{21}$ or $\mathrm{HE}_{12}$ mode. In this case, the pump and signal propagate in the fundamental modes.

a)
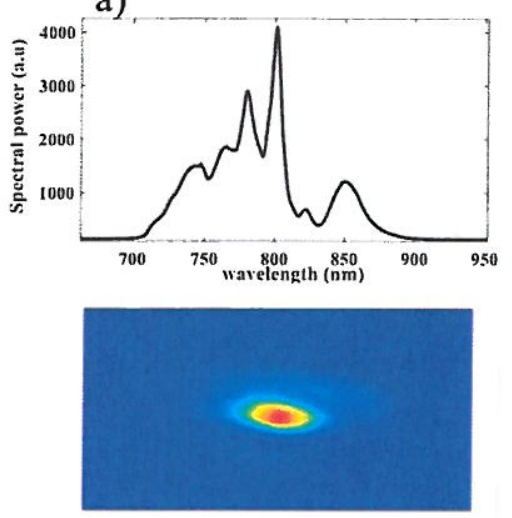

b)
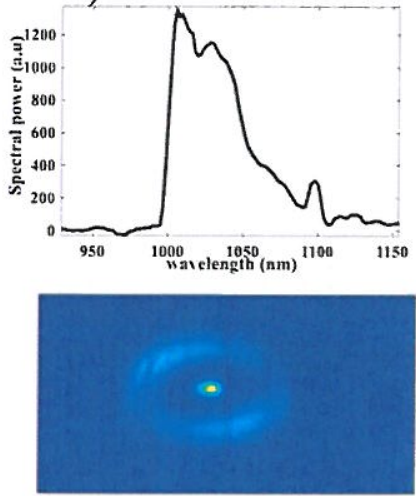

c)

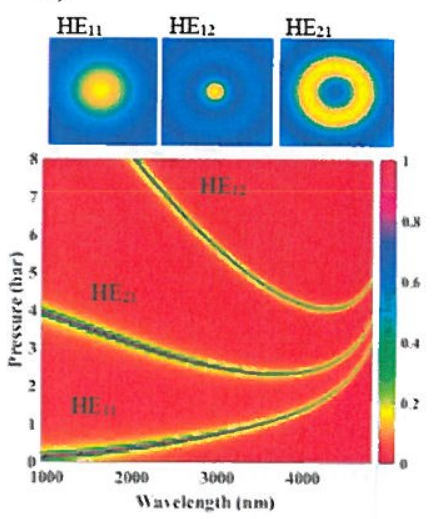

Figure 2. a) Spectrum and beam profile at the HCC output. b) Spectrum and beam profile when the highwavelength part is filtered. c). Calculated coherence length when the signal and pump (at $800 \mathrm{~nm}$ ) profile are in the fundamental modes and the infrared is in the HE11, HE12 or HE21 mode.

\section{Conclusion}

In this work, we investigate the modal FWM in an argon filled capillary apperaring simultaneously with SPM. This self-seeding effect is a very promising method to extend the spectral tunability with various modal phase-matching from a pump pulse in the fundamental mode.

\section{Acknowledgement}

ANR project (ANR-10-IDEX-03-02, ANR-17-EURE-0002) and Bourgogne Franche-Comté council (SUM Project).

\section{References}

[1] K. Krupa, A. Tonello, A. Barthélẻmy, V. Couderc, B. M. Shalaby. A. Bendahmane, G. Millot. S. Wabnitz, Phys. Rev. Lett. 116, 199902 (2016) [2] Z. Liu,L. G. Wright, D. N. Christodoulides, F. W. Wise, Opt. Lett. 41.3675 (2016)

[3] K. Krupa, A. Tonello, A. Barthélémy, T. Mansuryan. V. Couderc, G. Millot, P. Grelu.D. Modotto, S. A.Babin,S. Wabnitz, APL Photonics 4. 110901 (2019).

[4 ]A. Crego, E. Conejero, S. San Roman, Sc. Reports 9, 9546 (2019)

[5] T. Auguste, O. Gobert, C. Fourcade-Dutin, A. Dubrouil, E. Mevel, S. Petit, E. Constant, D. Descamps, J. Opt. Soc. Am. B 29, 1277 (2012) 